\title{
Sedative effects of Arachis hypogaea L. stem and leaf extracts on sleep-deprived rats
}

\author{
XIAOYAN ZU ${ }^{1}$, ZHENYA ZHANG ${ }^{2}$, GUANGQUAN XIONG $^{1}$, TAO LIAO ${ }^{1}$, \\ YU QIAO ${ }^{1}$, YITING $\mathrm{LI}^{2}$, SHENGRONG GENG ${ }^{1}$ and $\mathrm{XIN} \mathrm{LI}^{1}$ \\ ${ }^{1}$ Institute for Farm Products Processing and Nuclear-Agricultural Technology, Hubei Academy of Agricultural Sciences, \\ Wuhan, Hubei 430064, P.R. China; ${ }^{2}$ Graduate School of Life and Environmental Sciences, \\ University of Tsukuba, Tsukuba, Ibaraki 305-8572, Japan
}

Received March 15, 2013; Accepted June 4, 2013

DOI: $10.3892 /$ etm.2013.1182

\begin{abstract}
Arachis hypogaea L. stem and leaf extracts (AHSLE) are reputed to aid sleep. The purpose of this study was to evaluate the sedative effects of AHSLE on sleep-deprived (SD) rats and the effect on energy system pathways. Furthermore, we analyzed the essential oil components of Arachis hypogaea L. stems and leaves (AHSL) to explain the sedative effects. AHSLE were obtained by extracting AHSL twice with water at $98^{\circ} \mathrm{C}$ for $3 \mathrm{~h}$. Animal experiments were performed in the Laboratory Animal Resource Center, University of Tsukuba, Japan, and the levels of neurotransmitters were analyzed by high performance liquid chromatography (HPLC). The essential oil of the AHSL was obtained by simultaneous distillation and extraction (SDE) and analyzed by gas chromatography-mass spectrometry (GC-MS). Following treatment with AHSLE, the adenosine triphosphate (ATP) levels of the SD rats increased, which is a different effect from that previously observed in freely behaving rats. Adenosine (Ad) were not elevated by AHSLE uniformly throughout the brain, but accumulated in site-specific and time-prolonged manners. Following GC-MS analysis of the AHSL essential oil, a total of 37 compounds were identified; the major components were linalool $(16.17 \%$, which has sedative-like activity), $n$-hexadecanoic acid (16.42\%), and 1-octen-3-ol (8.48\%; a product of linalool decomposition). AHSLE affect the target neurotransmitters related to the rat circadian rhythms in specific brain regions, suggesting that AHSLE have the potential to increase sleep during the SD phase, and the sedative effects of AHSLE may be due to high levels of linalool and its decomposition products. AHSLE are potentially useful as sedatives or sleep aids in hypnotic therapy.
\end{abstract}

Correspondence to: Dr Xiaoyan $\mathrm{Zu}$, Institute for Farm Products Processing and Nuclear-Agricultural Technology, Hubei Academy of Agricultural Sciences, 5 South Lake Avenue, Wuhan, Hubei 430064, P.R. China

E-mail: xiaoyanzu@gmail.com

Key words: Arachis hypogaea L. stem and leaf, sedative effects, rat, sleep deprivation, linalool

\section{Introduction}

Arachis hypogaea L. stem and leaf extracts (AHSLE) have long had a reputation in China for easing various sleep disorders (1), and have been clinically validated by modern medicine $(2,3)$. Previous studies have focused solely on the clinical effects, and few studies have considered their mechanisms and active components.

We have previously reported (4) that AHSLE results in the consumption of adenosine triphosphate (ATP) and the accumulation of adenosine (Ad) in corresponding areas of the brain, in freely behaving rats. These findings raised questions as to whether the effects of AHSLE on the behavior of rats differ between spontaneous sleeping and sleep-deprived (SD) rats, and whether the changes to the concentration of $\mathrm{Ad}$ induced by AHSLE occurred throughout the brains of the rats or were limited to one or more regions, such as those regions known to be important for sleep regulation. These questions prompted the experiments conducted in the current study.

Since in animals, circadian rhythms are affected by the nervous system of the brain and neurotransmitters (5-7), in the current study, we measured three neurotransmitters of ATP, adenosine diphosphate (ADP) and Ad, using high performance liquid chromatography (HPLC). We also analyzed the essential oil components of Arachis hypogaea L. stems and leaves (AHSL) by gas chromatography-mass spectrometry (GC-MS). The results were used to evaluate the hypnotic effects of AHSL and identify its mechanisms of action.

\section{Materials and methods}

Plants, AHSLE and reagents. AHSL were collected from the banks of Yezi Lake, Wuhan, Hubei, China in August 2011. The plant was authenticated by the Agriculture and Forestry Research Center of Tsukuba University, Japan. It was cleaned, air-dried and passed through a 40-mesh standard sieve for extraction. The AHSLE were obtained by a previously described method (4). The AHSL were extracted twice with $98^{\circ} \mathrm{C}$ water ( $3 \mathrm{~h}$ each time), followed by filtration to remove residue. Brown powders were obtained through rotary evaporation and freeze drying of the supernatant. ATP, ADP and Ad standards were purchased from Sigma Chemical Co. 
(St. Louis, MO, USA). Other chemicals used were purchased from Wako Pure Chemical Industries, Ltd. (Osaka, Japan).

Animals. All animals and experiments were supported by the Laboratory Animal Resource Center of the University of Tsukuba, Japan. Male Sprague-Dawley rats (8 weeks old, $270 \pm 30 \mathrm{~g}$ ) were housed at $25^{\circ} \mathrm{C}$ with $12 \mathrm{~h}$ light/dark cycles (light on 08:00, light off 20:00), and food and water ad libitum. All rat experiments were performed in a humane manner after receiving approval from the Institutional Animal Experiment Committee of Tsukuba University, and in accordance with the regulations for animal experiments and fundamental guidelines under the jurisdiction of the Japanese Ministry of Education, Culture, Sports, Science and Technology.

Experimental protocols. In total, 34 rats were habituated in the animal lab for at least seven days, then randomly divided into two groups: the control group (water, $n=16$ ) and the AHSLE group [500 $\mathrm{mg} / \mathrm{kg}$ body weight $(\mathrm{BW}), \mathrm{n}=18]$. Based on the method described previously (8) with certain modifications, the rats in the AHSLE group were randomly divided into three subgroups: SD-2.5 $\mathrm{h}(\mathrm{n}=6), \mathrm{SD}-5 \mathrm{~h}(\mathrm{n}=6)$ and recovery (Rec)-3 h (n=6). All drug administration was conducted intragastrically (i.g.) for 14 days at a dose of $500 \mathrm{mg} / \mathrm{kg} \mathrm{BW}$ before 8:00 a.m. (prior to the start of the light phase). On the 14th day, following drug administration, SD was achieved by the gentle handling method, as described previously (9). Rats were continuously inspected and SD was realized by tapping the cage lightly or touching the animal with a paintbrush. SD for $2.5 \mathrm{~h}$ or $5 \mathrm{~h}$ was started at 8:00 a.m. and performed under 'lights-on' conditions. The $3 \mathrm{~h}$ Rec started once the rats had been deprived of sleep for $5 \mathrm{~h}$. The SD and Rec groups each had their own control group $(n=5-6)$ of rats, which were treated under the same conditions.

Following the trials, the rats were anaesthetized with an intraperitoneal injection of urethane $(200 \mathrm{mg} / \mathrm{ml}, 0.5 \mathrm{ml} / 100 \mathrm{~g}$ $\mathrm{BW}$ ), and dissected rapidly to isolate the whole brains. To verify the differences in neurotransmitters at diverse brain regions, the entire brain was separated into three regions: the cerebrum, brainstem (midline involving thalamus and hypothalamus) and cerebellum. Considering the brain responses to nucleoside and nucleotide synthesis, the brain tissues were frozen immediately and stored at $-80^{\circ} \mathrm{C}$, prior to analyzing the target neurotransmitters.

ATP, ADP and Ad analysis. ATP, ADP and Ad were analyzed by HPLC (JASCO International Co., Ltd, Tokyo, Japan). Rat brain samples were homogenized at $4^{\circ} \mathrm{C}$ with trichloroacetic acid (TCA) at a final concentration of $25 \%(\mathrm{v} / \mathrm{v})$ and centrifuged to remove protein sediment. Supernatants were subsequently neutralized to $\mathrm{pH}$ 5-6 with $\mathrm{NaOH}$, following filtration (0.45 $\mu \mathrm{m}$ membrane). Analyses of the brain neurotransmitters, ATP, ADP and Ad, were performed according to previously reported methods (10) with minor modifications. The samples were analyzed by HPLC with a Capcell-Pak C18 column [4.6 $\mathrm{mm}$ internal diameter (I.D.) x $150 \mathrm{~mm}$, particle size $5 \mu \mathrm{m}$ ] at a flow rate of $1 \mathrm{ml} / \mathrm{min}$ and detected at $254 \mathrm{~nm}$. The mobile phase consisted of a gradient mixture with solvent $\mathrm{A}(0.1 \mathrm{~mol} / \mathrm{l}$ $\mathrm{NH}_{4} \mathrm{H}_{2} \mathrm{PO}_{4}$ solution) and $\mathrm{B}[20 \%(\mathrm{v} / \mathrm{v})$ methanol $(99.7 \%)$ in solvent A]. During testing, the gradient was as follows:
0 min, $0 \% \mathrm{~B} ; 6-18 \mathrm{~min}, 35 \% \mathrm{~B} ; 26 \mathrm{~min}, 0 \% \mathrm{~B}$. The flow-rate was $1 \mathrm{ml} / \mathrm{min}$ with an injection volume of $20 \mu \mathrm{l}$. The ATP, ADP and Ad standard were 100, 100 and $25 \mu \mathrm{mol} / 1$, respectively, in concentration and diluted by five gradients, respectively. In the brain samples, ATP and its metabolites were calculated by comparing peak areas and the appropriate standard curves.

Essential oil extraction. Simultaneous distillation and extraction (SDE) was used to extract the essential oil from the AHSL. Petroleum ether and distilled water were used as low- and high-density solvents (contained $30 \mathrm{~g}$ AHSL/80 ml), respectively. The low- and high-density distillers for SDE were simultaneously heated by electric sets, so that the steam from the two distillers mixed with each other at the top of the glass instrument and subsequently divided into aqueous and petroleum ether layers. The petroleum ether layer with the essential oil from AHSL flowed to the low-density distiller and the aqueous layer flowed to the high-density distiller. The cyclical process was continued for 5-6 h, and three $30 \mathrm{~g}$ samples of AHSL were extracted by this method. The essential oil obtained was merged, following the removal of trace water by treatment with anhydrous $\mathrm{Na}_{2} \mathrm{SO}_{4}$. Following rotary evaporation, the essential oil in the petroleum ether was stored at $-20^{\circ} \mathrm{C}$.

Chemical analysis of the essential oil. The essential oil in the petroleum ether was analyzed using an Agilent $7890 \mathrm{~A}$ chromatograph (Agilent Technologies Inc., Santa Clara, CA, USA) coupled with a 5975 network mass selective detector and equipped with a HP-5 capillary fused silica column (30 m x $0.25 \mathrm{~mm}$ I.D. x $0.25 \mu \mathrm{m}$ film thickness). The oven temperature was maintained at $80^{\circ} \mathrm{C}$ for $5 \mathrm{~min}$, and then programmed to increase at a rate of $4^{\circ} \mathrm{C} / \mathrm{min}$ to $280^{\circ} \mathrm{C}$. Other operating conditions were as follows: carrier gas, $\mathrm{He}$ (99.999\%) with a flow rate of $1 \mathrm{ml} / \mathrm{min}$; injector temperature, $250^{\circ} \mathrm{C}$; split ratio, 1:50; and injection volume, $1 \mu \mathrm{m}$. The mass spectra were recorded at $70 \mathrm{eV}$ with a mass range from $\mathrm{m} / \mathrm{z}$ 20-500.

The linalool standard was at concentrations of 6.25 , $12.5,25,50,100$ and $200 \mu \mathrm{g} / \mathrm{ml}$, with an internal standard of cyclohexanone with a final concentration of $100 \mu \mathrm{g} / \mathrm{ml}$. The linalool standard was analyzed by the method mentioned previously with the modification that the oven temperature was maintained at $80^{\circ} \mathrm{C}$ for $5 \mathrm{~min}$ and was then programmed to increase at $4^{\circ} \mathrm{C} / \mathrm{min}$ to $160^{\circ} \mathrm{C}$. The concentration of linalool in the essential oil was calculated by comparing the peak area and the appropriate standard curve.

Statistical analysis. The data were analyzed using a two-tailed Student's t-test and the results are expressed as the means \pm standard deviation. $\mathrm{P}<0.05, \mathrm{P}<0.01$ and $\mathrm{P}<0.001$ are considered to indicate statistically significant differences.

\section{Results}

Brain ATP levels during SD and Rec sleep. It was demonstrated that in the AHSLE groups, brain ATP levels increased with SD time and decreased following $3 \mathrm{~h}$ Rec (Fig. 1). In the cerebrum and cerebellum, the ATP levels were reduced in the SD-2.5 $\mathrm{h}$ group, while they were increased in the SD-5 $\mathrm{h}$ 


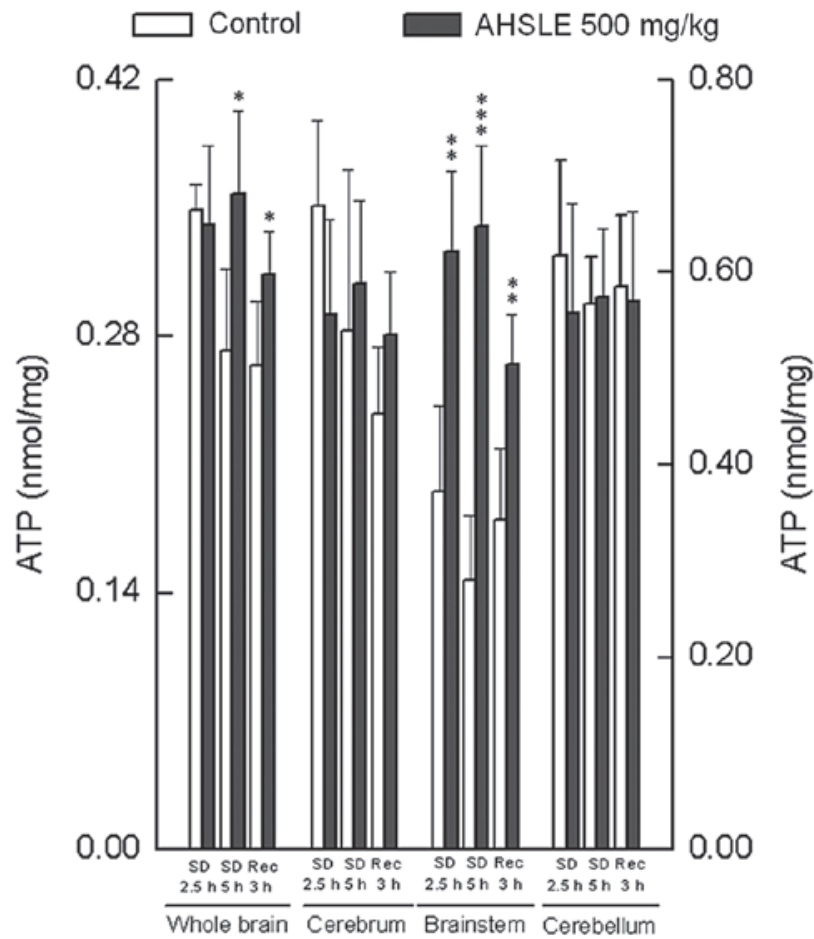

Figure 1. Adenosine triphosphate (ATP) concentrations in different brain regions during SD and Rec sleep. The principal y-axis represents the ATP level of the whole brain, cerebrum and brainstem. The secondary y-axis represents the ATP level of the cerebellum. Each column represents the mean with standard deviation. The significance of the effects of the treatment was assessed using the Student's t-test. ${ }^{*} \mathrm{P}<0.05,{ }^{* * *} \mathrm{P}<0.01$ and $^{* * * *} \mathrm{P}<0.001$ compared with the respective controls (open bars). SD, sleep-deprived; Rec, recovery.

group, compared with the respective controls. ATP levels were enhanced significantly $(\mathrm{P}<0.01)$ in the brainstems of the AHSLE-treated rats compared with the controls.

Brain ADP levels during SD and Rec sleep. As the results (Fig. 2) demonstrated, the ADP levels decreased with increased SD time in the AHSLE and control groups. Following the administration of AHSLE, the ADP levels were enhanced during the SD phase compared with the respective control and the $3 \mathrm{~h}$ Rec did not increase the ADP values to normal levels.

Brain Ad levels during SD and Rec sleep. According to the results (Fig. 3), the Ad values in the AHSLE groups increased with SD time in all brain regions in addition to the entire brain, and then reduced following $3 \mathrm{~h}$ Rec sleep. Following the administration of AHSLE, the Ad variation trend was similar to that of ATP; Ad accumulated in the brainstem and cerebellum during the SD phase. Contrasting results were observed in the control groups.

Composition of AHSL essential oil. As can be seen in Table I, a total of 37 compounds were identified, and the major components were 3,7-dimethyl-1,6-octadien-3-ol (linalool, 16.17\%), $n$-hexadecanoic acid (16.42\%), 1-octen-3-ol (product of linalool decomposition, 8.48\%,), 1,2,3-trimethylbenzene (6.56\%), phytol (6.34\%), 2-methoxy-4-vinylphenol (4.70\%), 6,10,14-trimethyl-2-pentadecanone (3.96\%), $\alpha, \alpha, 4$-trimethyl-3 cyclohexene-1-methanol (3.80\%), 1-ethyl-

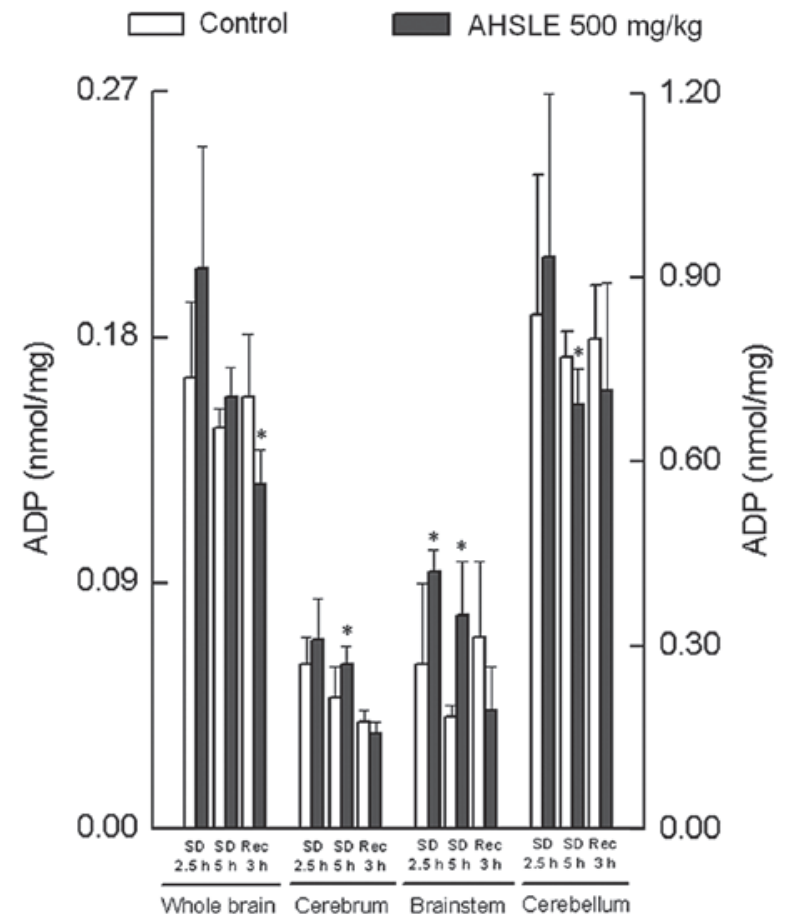

Figure 2. Adenosine diphosphate (ADP) concentrations in different brain regions during $\mathrm{SD}$ and $\mathrm{Rec}$ sleep. The principal y-axis represents the ADP level of the whole brain, cerebrum and brainstem. The secondary y-axis represents the ADP level of the cerebellum. Each column represents the mean with standard deviation. The significance of the effects of the treatment was assessed using the Student's t-test. $\mathrm{P}<0.05$ compared with the respective controls (open bars). SD, sleep-deprived; Rec, recovery.

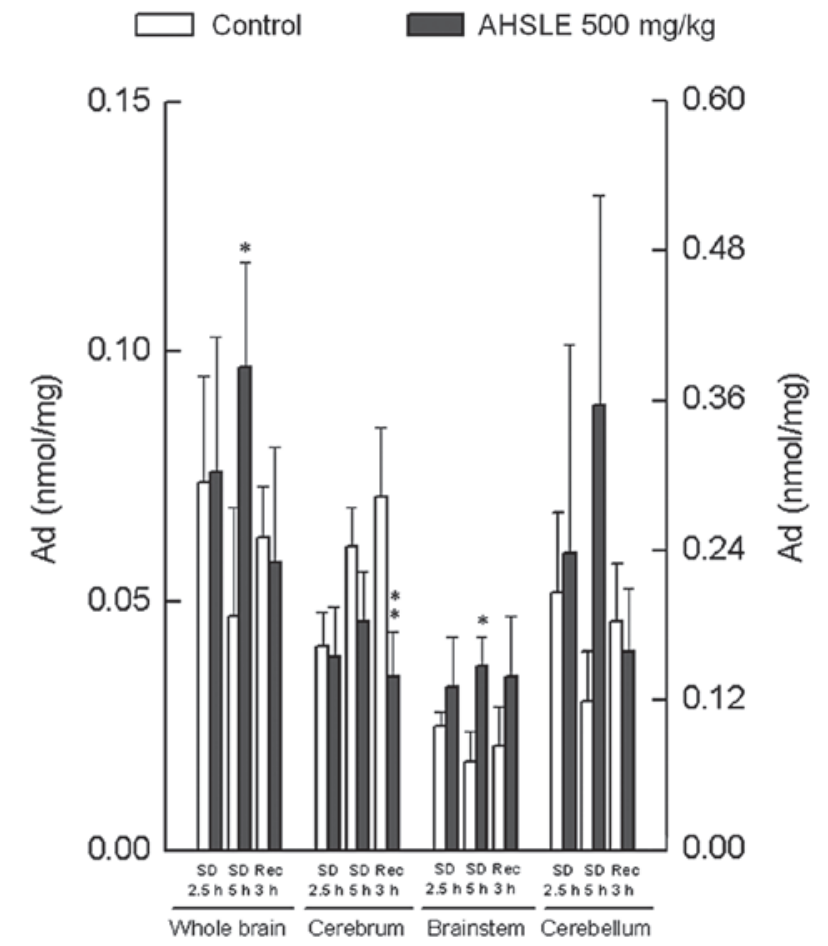

Figure 3. Adenosine (Ad) concentrations in different brain regions during $\mathrm{SD}$ and Rec sleep. The principal y-axis represents the Ad level of the whole brain, cerebrum, and brainstem. The secondary y-axis represents the Ad level of the cerebellum. Each column represents the mean with standard deviation. The significance of the effects of the treatment was assessed using the Student's t-test. ${ }^{*} \mathrm{P}<0.05$ and ${ }^{* * *} \mathrm{P}<0.01$ compared with the respective controls (open bars). SD, sleep-deprived; Rec, recovery. 
Table I. Components identified in the essential oil of AHSL by GC-MS analysis.

\begin{tabular}{|c|c|c|c|c|}
\hline Number & $\begin{array}{l}\text { Retention time } \\
\text { (min) }\end{array}$ & Compound & Peak area $\left(\times 10^{5}\right)$ & 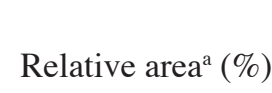 \\
\hline 1 & 2.310 & (E)-2-Hexenal & 0.190 & 0.52 \\
\hline 2 & 2.503 & $p$-Xylene & 0.620 & 1.69 \\
\hline 3 & 3.740 & 1-Ethyl-2-methylbenzene & 1.371 & 3.74 \\
\hline 4 & 3.984 & 1-Octen-3-ol & 3.109 & 8.48 \\
\hline 5 & 4.285 & 2-Pentylfuran & 0.231 & 0.63 \\
\hline 6 & 4.405 & 1,2,3-Trimethylbenzene & 2.403 & 6.56 \\
\hline 7 & 5.148 & 1,3,5-Trimethylbenzene & 1.076 & 2.94 \\
\hline 8 & 5.290 & Limonene & 0.093 & 0.25 \\
\hline 9 & 5.738 & Benzeneacetaldehyde & 1.031 & 2.81 \\
\hline 10 & 6.590 & cis-Linalool oxide & 1.297 & 3.54 \\
\hline 11 & 7.004 & 1-Ethyl-2,4-dimethylbenzene & 0.082 & 0.22 \\
\hline 12 & 7.435 & 3,7-Dimethyl-1,6-octadien-3-ol (linalool) & 5.929 & 16.17 \\
\hline 13 & 7.594 & 3,7-Dimethyl-1,5,7-octatrien-3-ol & 0.343 & 0.94 \\
\hline 14 & 10.591 & $\alpha, \alpha$-4-trimethyl-3-cyclohexene-1-methanol & 1.393 & 3.80 \\
\hline 15 & 10.789 & (-)-Myrtenol & 0.248 & 0.68 \\
\hline 16 & 11.936 & 2,7-Dimethyl-2,6-octadien-1-ol & 0.180 & 0.49 \\
\hline 17 & 12.855 & (E)-3,7-Dimethyl-2,6-octadien-1-ol & 0.600 & 1.64 \\
\hline 18 & 14.910 & 2-Methoxy-4-vinylphenol & 1.721 & 4.70 \\
\hline 19 & 17.231 & 1-(2,6,6-Trimethyl-1,3-cyclohexadien-1-yl)-2-buten-1-one & 0.245 & 0.67 \\
\hline 20 & 20.466 & N-(4-methoxyphenyl)-2-propenamide & 0.390 & 1.06 \\
\hline 21 & 21.771 & 5,6,7,7a-Tetrahydro-4,4,7a-trimethyl-2(4H)-benzofuranone & 0.203 & 0.55 \\
\hline 22 & 22.827 & (E)-3,7,11-Trimethyl-1,6,10-dodecatrien-3-ol & 0.377 & 1.03 \\
\hline 23 & 23.854 & Trichloroacetic acid, 3-methylbutyl ester & 0.549 & 1.43 \\
\hline 24 & 29.092 & Sulfurous acid, 2-propyl tridecyl ester & 0.159 & 0.43 \\
\hline 25 & 29.319 & 2,6,10-Trimethyl-dodecane & 0.180 & 0.49 \\
\hline 26 & 30.148 & 6,10,14-Trimethyl-2-pentadecanone & 1.451 & 3.96 \\
\hline 27 & 30.676 & Phthalic acid, isobutyl octadecyl ester & 0.171 & 0.47 \\
\hline 28 & 31.334 & Tritetracontane & 0.391 & 1.07 \\
\hline 29 & 31.777 & 6,10,14-Trimethyl-(E,E)-5,9,13-pentadecatrien-2-one & 0.225 & 0.61 \\
\hline 30 & 31.919 & Hexadecanoic acid, methyl ester & 0.463 & 1.26 \\
\hline 31 & 32.724 & $n$-Hexadecanoic acid & 6.017 & 16.42 \\
\hline 32 & 35.256 & 11,14-Eicosadienoic acid methyl ester & 0.358 & 0.98 \\
\hline 33 & 35.375 & 12-Methyl-E,E-2,13-octadecadien-1-ol & 0.513 & 1.40 \\
\hline 34 & 35.613 & Phytol & 2.324 & 6.34 \\
\hline 35 & 38.905 & 3-Ethyl-5-(2-ethylbutyl)octadecane & 0.302 & 0.83 \\
\hline 36 & 40.568 & Heptacosane & 0.220 & 0.60 \\
\hline \multirow[t]{2}{*}{37} & 42.157 & Eicosane & 0.204 & 0.56 \\
\hline & & Total & 36.659 & 99.96 \\
\hline
\end{tabular}

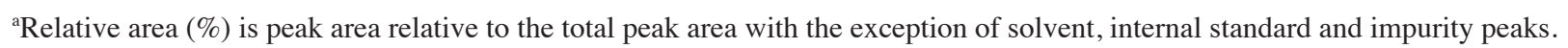

2-methylbenzene $(3.74 \%)$, cis-linalool oxide $(3.54 \%)$, 1,3,5-trimethylbenzene $(2.94 \%)$ and benzeneacetaldehyde (2.81\%; Table I). These 12 major components accounted for $79.46 \%$ of the yield, while other identified constituents represented $<2 \%$. The linalool standard curve obtained was $\mathrm{Y}=2926.4 \mathrm{x}-16702, \mathrm{R}^{2}=0.9997$. According to the peak area and standard curve, the linalool concentration in petroleum ether was $\sim 10.415 \mathrm{mg} / \mathrm{ml}$, and yield was $\sim 578.611 \mathrm{mg} / \mathrm{kg}$ AHSL.

\section{Discussion}

ATP is the direct source of energy for cellular activity. ADP may be converted into ATP or degraded to Ad (11). Energy depletion may increase the need to sleep (12). The ATP results for the control group (Fig. 1) indicate that brain levels of ATP decreased with increasing SD time in the whole brain and $3 \mathrm{~h}$ of Rec sleep was insufficient to replenish the energy lost. In contrast to the SD-2.5 $\mathrm{h}$ control group, the ATP levels in the AHSLE-2.5 $\mathrm{h}$ 
group increased in the brainstem while they decreased in the cerebrum and cerebellum, which revealed the preferential provision of energy to the central area and indicated that energy deficiency in the cerebrum and cerebellum may establish the need to sleep. When AHSLE were administered, the ATP levels of the SD rats increased, which is different from the effect previously observed in freely behaving rats (4); this may be due to state-related changes to the stress reactions of the rats.

Ad is a crucial neurotransmitter in the sleep system of the brain (13); it accumulates in the brain and has been proposed as an important factor for homeostatic sleep (14). In AHSL-treated $\mathrm{SD}$ rats, the observed increases in the concentrations of $\mathrm{Ad}$ in all regions of the brain reflected the bio-energetic stress of the animals. Furthermore, $3 \mathrm{~h}$ of Rec sleep was sufficient to reduce the sleep propensity signal (Ad) to the levels observed during normal wakefulness, following the administration of AHSLE.

The purine nucleoside, Ad, has been reported to be a candidate sleep factor, as systemic injections of Ad were observed to promote sleep and reduce wakefulness (15). The concentrations of Ad have also been reported to increase with increased metabolism and neural activity (16,17). In the current study, in SD rats, Ad accumulated as a product of increased metabolism/neural activity, to inhibit neural activity in various brain regions and was then consumed during the recovery of sleep.

The current study demonstrated that, during sleep deprivation, Ad accumulated in a site-specific and time-prolonged manner. In the brain stem and cerebellum, Ad levels in the AHSLE groups increased steadily and significantly during the SD phase, compared with basal and SD-2.5 h levels. By contrast, the cerebrum did not demonstrate an accumulation of Ad during the SD phase following the administration of AHSLE, indicating that, during prolonged wakefulness, Ad levels are not uniformly elevated by AHSLE throughout the brain. These findings support the hypothesis that an increase in the need to sleep enhances the release of cortical Ad. It indicates that the cerebellum and brainstem are critical sites of Ad action. Thus, these data revealed that during sleep deprivation, AHSLE stimulates Ad accumulation selectively in the cerebellum and, to a lesser extent, in the brainstem.

Regarding the effective components, we analyzed the composition of the essential oil of AHSL according to a previously described method (18). Naturally occurring linalool may be transformed into a number of derivatives that are valuable to the flavour and fragrance industries $(19,20)$, and has demonstrated antidepressant- and sedative-like activity (21). The sedative effect of linalool-rich essential oils is suggested to provoke a reduction in neuronal excitability (22). Our analysis of the essential oil components of AHSL indicated a high linalool content, which may be the source of the sedative effects.

In conclusion, this site-specific accumulation of Ad during sleep deprivation indicates the physiological regulatory effect of AHSLE. Cumulative evidence suggests that AHSLE increases the levels of Ad in the brain during sleep deprivation, which has the potential to increase sleep. The sedative effects of AHSL may be attributed to their high linalool content.

\section{References}

1. Wang QC, Xu J, Shi M, et al: Clinical observation of preparation from the branch and leaf of peanut in treating insomnia. Shanghai J Trad Chin Med 5: 8-10, 2001 (In Chinese).
2. Hu PF, Fan RP, Li YP and Pang CY: Studies on pharmacological action of Luohuashengzhiye extract. Chin Trad Pat Med 23: 919920, 2001 (In Chinese)

3. Wang YF, Li HF, XuYF, Zhang YL, Xu DS, Xiao LM and Li XM: Clinical confirmation of preparation from the branch and leaf of peanut in treating insomnia. Shanghai J Trad Chin Med 5: 11-14, 2001 (In Chinese).

4. Zu XY, Zhang ZY, Liu JQ, Hu HH, Xing GQ, Zhang Y and Guan D: Sedative effects of peanut (Arachis hypogaea L) leaf aqueous extracts on brain ATP AMP, adenosine and glutamate/GABA of rats. J Biomed Sci Eng 3: 268-273, 2010.

5. Sherin JE, Shiromani PJ, McCarley RW and Saper CB: Activation of ventrolateral preoptic neurons during sleep. Science 271: 216-219, 1996

6. Gaus SE, Strecker RE, Tate BA, Parker RA and Saper CB: Ventrolateral preoptic nucleus contains sleep-active galaninergic neurons in multiple mammalian species. Neuroscience 115: 285-294, 2002.

7. Sherin JE, Elmquist JK, Torrealba F and Saper CB: Innervation of histaminergic tuberomammillary neurons by GABAergic and galaninergic neurons in the ventrolateral preoptic nucleus of the rat. J Neurosci 18: 4705-4721, 1998.

8. Wigren HK, Schepens M, Matto V, Stenberg D and Porkka-Heiskanen T: Glutamatergic stimulation of the basal forebrain elevates extracellular adenosine and increases the subsequent sleep. Neuroscience 147: 811-823, 2007.

9. Franken P, Dijk DJ, Tobler I and Borbély AA: Sleep deprivation in rats: effects on EEG power spectra, vigilance states, and cortical temperature. Am J Physiol 261: R198-R208, 1991.

10. Schweinsberg PD and Loo TL: Simultaneous analysis of ATP, ADP, AMP, and other purines in human erythrocytes by highperformance liquid chromatography. J Chromatogr 181: 103-107, 1980.

11. Dworak M, Diel P, Voss S, Hollmann WK and Strüder H: Intense exercise increases adenosine concentrations in rat brain: implications for a homeostatic sleep drive. Neuroscience 150: 789-795, 2007.

12. Thakkar MM, Engemann SC, Walsh KM and Sahota PK: Adenosine and the homeostatic control of sleep: effects of A1 receptor blockade in the perifornical lateral hypothalamus on sleep-wakefulness. Neuroscience 153: 875-880, 2008.

13. Huang ZL, Urade Y and Hayaishi O: Prostaglandins and adenosine in the regulation of sleep and wakefulness Curr Opin Pharmacol 7: 33-38, 2007

14. Kalinchuk AV, Urrila AS, Alanko L, Heiskanen S, Wigren HK, Suomela M, Stenberg D and Porkka-Heiskanen T: Local energy depletion in the basal forebrain increases sleep. Eur J Neurosci 17: 863-869, 2003.

15. Ticho SR and Radulovacki M: Role of adenosine in sleep and temperature regulation in the preoptic area of rats. Pharmacol Biochem Behav 40: 33-40, 1991.

16. Radulovacki M: Role of adenosine in sleep in rats. Rev Clin Basic Pharm 5: 327-339, 1985.

17. Van Wylen DG, Park TS, Rubio R and Berne RM: Increases in cerebral interstitial fluid adenosine concentration during hypoxia local potassium infusion and ischemia. J Cereb Blood Flow Metab 6: 522-528, 1986.

18. Jalali Heravi M and Sereshti H: Determination of essential oil components of Artemisia haussknechtii Boiss. using simultaneous hydrodistillation-static headspace liquid phase microextractiongas chromatography mass spectrometry. J Chromatogr A: 1160: 81-89, 2007.

19. Letizia CS, Cocchiara J,Lalko J and Api AM: Fragrance material review on linalool. Food Chem Toxicol 41: 943-964, 2003.

20. Simić A, Soković MD, Ristić M, Grujić-Jovanović S, VukojevićJ and Marin PD: The chemical composition of some Lauraceae essential oils and their antifungal activities. Phytother Res 18: 713-717, 2004.

21. Guzmán-Gutiérrez SL, Gómez-Cansino R, García-Zebadúa JC, Jiménez-Pérez NC and Reyes-Chilpa R: Antidepressant activity of Litsea glaucescens essential oil: identification of $\beta$-pinene and linalool as active principles. J Ethnopharmacol 143: 673-679, 2012.

22. de Almeida RN, Araújo DA, Gonçalves JC, Montenegro FC, de Sousa DP, Leite JR, Mattei R, Benedito MA, de Carvalho JG, Cruz JS and Maia JG: Rosewood oil induces sedation and inhibits compound action potential in rodents. J Ethnopharmacol 124: 440-443, 2009. 